\title{
WestVirginiaUniversity.
}

Department of Economics

Working Paper Series

\section{Bargaining in the Shadow of Arbitration}

Riccardo Marselli, Bryan McCannon and Marco Vannini

Working Paper No. 15-19

This paper can be found at the College of Business and Economics Working Paper Series homepage: 


\title{
Bargaining in the Shadow of Arbitration
}

\author{
Riccardo Marselli \\ Parthenope University ${ }^{+}$
}

\author{
Bryan C. McCannon \\ West Virginia University ${ }^{ \pm}$ \\ \& Center for Free Enterprise
}

Marco Vannini

University of Sassari*

30 April $2015^{*}$

\begin{abstract}
Arbitration, as an alternative to litigation for contract disputes, reduces costs and time. While it has frequently been thought of as a substitute to pretrial bargaining and litigation, in fact, parties may be able to reach a settlement privately while engaged in the arbitration process.

Consequently, the institutional design may influence the bargaining. We develop a theoretical model of pre-arbitration bargaining that is able to identify the impact of the institutional features on its success. A detailed data set from arbitration proceedings in Italy is analyzed. The exogenous heterogeneity in the composition of the panel of arbitrators allows us to illustrate its effect on bargaining. We show that the number of arbitrators used interacts with their experience and independence to reduce uncertainty and facilitate settlement.
\end{abstract}

\section{JEL codes: K41, C78}

Keywords: arbitration, bargaining, contract dispute, conventional arbitration, Italy, settlement

\footnotetext{
${ }^{+}$Department of Economics, Parthenope University, 40 via Medina, 80133 Napoli, Italy, riccardo.marselli@uniparthenope.it

${ }^{ \pm}$corresponding author: Department of Economics, West Virginia University, 1601 University Avenue, Morgantown, WV 26506, U.S.A., bryan.c.mccannon@gmail.com; (607) 857-7411

*University of Sassari, 34 via Torre Tonda, 07100 Sassari, Italy, vannini@uniss.it

${ }^{*}$ We greatly acknowledge the Camera Arbitrale Milano and its Deputy-Secretary General Rinaldo Sali and his staff for providing the data. We also thank Alessio Scano for discussions of arbitration and civil law in general of Italy. Finally, we thank participants of the Conference on Empirical Legal Studies, Guiseppe Dari-Mattiacci, Geoff Miller, Paul Pecorino, and Don Swanz for helpful discussions and suggestions.
} 


\section{Introduction}

When a contract dispute arises publicly-provided systems for litigation are available. Litigation, though, utilizes substantial amounts of public resources, suffers from high opportunity costs for the time of the disputants, judge, court personnel and jurors, and drains private resources. Due to these costs, parties to a dispute have the incentive to privately resolve the conflict through pre-trial bargaining. Settlement via pre-trial negotiations is imperfect though. This "bargaining in the shadow of the law" (Cooter, Marks, and Mnookin, 1982) has encouraged a rich literature, focusing on optimism bias and asymmetric information, to explain the bargaining failures. Given these failures, there has been much interest in alternative dispute resolution (ADR) as a substitute to the bargaining-litigation framework. One common form of ADR is binding arbitration where the parties to a contract agree ex ante to resolve any potential dispute with a third-party arbitrator or panel of arbitrators who, after reviewing the evidence and arguments, select an outcome.

The dichotomy between ADR and pre-litigation bargaining has been set out by DariMattiacci (2007). He explores the factors that encourage parties to ex ante commit to arbitration rather than leave the contract 'more-incomplete' relying on pre-trial bargaining. While an important question worthy of additional investigation, one must recognize that private resolutions are not separate from the arbitration process, but nested within. Bargaining may occur in the shadow of arbitration as well. ${ }^{1}$

Our objective is to explore the issue of bargaining over contract disputes when failure results in an arbitration decision. The institutional features of arbitration vary. Who acts as an arbitrator? Should a panel be employed rather than a single decisionmaker? Failures of private resolutions are typically argued to be due to uncertainty. Consequently, how the institutional design affects the uncertainty and, as a result, facilitates private resolutions is an important public policy question.

We develop a straightforward theoretical model of bargaining in the shadow of arbitration that combines the intuition of the Condorcet Jury Theorem (Mueller, 2003) regarding the optimality of group decisionmaking with the economics of uncertainty in bargaining. This

\footnotetext{
${ }^{1}$ A complementary analysis is done by Spurr (2000) considering nonbinding mediation, but with litigation as the default outcome.
} 
allows us to identify which factors influence private resolution. We then analyze a data set of arbitration cases of the Chamber of Commerce in Milan, Italy (Camera di Commercio). It is common practice to include a clause in contracts in Italy to utilize the chamber's arbitration service (known as the Clausola Compromissoria) The parties agree upfront on features of the arbitration process and, hence, the institutional design is exogenous to the dispute. After filing, the composition/identity of the arbitrators is determined. Many, but not all, of the disputes are then resolved. Thus, characteristics of the disputes, the actors, and (importantly) the institutional features can be used to explain whether or not bargaining is successful.

The theoretical model predicts that the uncertainty associated with the unknown quality of the decisionmaking of an arbitrator is muted when a panel of arbitrators is used. The mitigated uncertainty facilitates private resolutions. Empirical evidence is presented confirming this hypothesis. The likelihood of a case continuing all the way until a decision is handed down by the arbitrators is significantly less likely when a panel of three arbitrators is employed rather than only one. Additionally, a result of the theoretical model is that amongst three arbitrator panels, if there are divergent beliefs regarding the decisionmaking of two arbitrators, uncertainty and bargaining failures are more likely than if there is only heterogeneity in assessments over one arbitrator. In Italy, arbitrators tend to be either privately-practicing attorneys or university law professors. The latter have more education, publicly-available scholarship, and in general have a better reputation for quality decisionmaking. The empirical results show that if the majority of the panel of arbitrators are professors, then the likelihood of the dispute persisting until the completion of the arbitration process is significantly reduced. Hence, the empirical results conform to the theoretical predictions that the number of arbitrators and the confidence in the decisionmaking ability of those selected reduces uncertainty and facilitates private bargaining.

Ours, though, is not the first paper to consider bargaining within an arbitration framework. Early work by Crawford $(1979 ; 1982)$ addresses settlement with an arbitrator resolving any dispute that persists. He compares conventional arbitration, where the arbitrator selects her most preferred outcome, to final-offer arbitration, with the arbitrator restricted to selecting amongst the final offers made by the disputants. In his framework bargaining always succeeds, as the outcome under arbitration is known when bargaining. Exploring bargaining failure, Farmer and Pecorino (1998) consider final-offer arbitration where the parties to the dispute have asymmetric information regarding the expected decision of the arbitrator. They 
illustrate that offers can provide information to the other party. ${ }^{2}$ Allowing for bargaining after the offers are made facilitates settlement. ${ }^{3}$ Extending the analysis to include the voluntary revelation of private information, Farmer and Pecorino (2003) illustrate that the transmission of information can be used by the uninformed party to make a better final offer. Therefore, the informed party has the incentive to withhold private information, which could have promoted settlement. Again, if bargaining is allowed after final offers are submitted, but before the arbitrator makes her decision, then all disputes settle. Experimental evidence supports these findings (Van Boening and Pecorino, 2001). Deck and Farmer (2009) consider the complementary issue of investments in arbitration cases.

Our work should be seen as a complement to the valuable contributions of asymmetric information models of bargaining and arbitration. We consider (symmetric) uncertainty of the disputants. ${ }^{4}$ The emphasis here is on differing institutional arrangements and how the arbitration setup exacerbates or mitigates the uncertainty, affecting the private resolution of conflicts. Furthermore, the strategic informational issues arise primarily in final-offer arbitration where the arbitrator is bound to one of the two proposals. We consider conventional arbitration institutions here, which are common in contract disputes such as those utilized in international trade agreements in Europe.

Furthermore, the theoretical model considers group decisionmaking and, therefore, as stated, builds off of the insights of the Condorcet Jury Theorem (CJT) (see Young (1988), Mueller (2003), and McCannon (2015) for detailed discussion). The CJT considers the accuracy of a group's decision when the size of the group expands. Stated broadly, the CJT illustrates that the decision reached by a group becomes more accurate as the size of the group increases. ${ }^{5}$ The tradeoff between accuracy and the costs to group size is considered in McCannon (2011). Here, the interaction between the accuracy of the group and the private bargaining is addressed.

\footnotetext{
${ }^{2}$ Farmer Curry and Pecorino (1993) similarly consider asymmetric information regarding risk preferences of the disputants.

${ }^{3}$ In their framework, settlement does not arise in $100 \%$ of the cases in the separating equilibrium. Since the rate of settlement increases in these outcomes with renegotiation, but the set of pooling equilibrium (where settlement always occurs) reduces, the net effect on settlement rates is ambiguous.

${ }^{4}$ Deck and Farmer (2007) consider symmetric uncertainty and bargaining as well. Their framework generates nonempty bargaining zones and, therefore, is unable to explain bargaining failure. Their experimental research addresses whether settlement rates are correlated with the size of the bargaining zone.

${ }^{5}$ There is an expansive literature investigating both asymptotic and non-asymptotic versions of the CJT and with various relaxations of the assumptions (e.g. majority voting, independent assessments, etc.).
} 
Previous empirical work has compared conventional and final-offer arbitration used for New Jersey fire and police employees (Ashenfelter and Bloom, 1984), surveyed practicing arbitrators (Farber and Bazerman, 1986), investigated strike frequency with differing legislation on arbitration (Currie and McConnell, 1994), examined transfer markets in English football (Speight and Thomas, 2003), studied disputes in Major League Baseball (Farmer, Pecorino, and Stango, 2004), and evaluated the impact of legal representation (Ashenfelter and Dahl, 2012; Ashenfelter, Bloom and Dahl, 2013) to name a few. Case studies have discussed arbitration in the diamond industry (Bernstein, 1992) and private resolutions of contract disputes in Vietnam (McMillan and Woodruff, 1999). Our work also shares similarities with Lederman (1999) who uses U.S. Tax Court data to identify which factors lead to settlement versus go to trial. Her study does not consider arbitration or allow for an institutional analysis.

We first build a theoretical model in Section 2 to form testable hypotheses regarding arbitration mechanisms and settlement. Section 3 provides details of arbitration conducted in Milan, Italy and describes the data collected. The econometric results are provided in Section 4, while Section 5 concludes.

\section{Theoretical Model}

The objective is to provide a simple, straightforward model able to integrate theories of uncertainty in bargaining within a framework of group decisionmaking. Doing so will allow us to assess the impact of the composition of the council of arbitrators on bargaining.

First, the preliminaries of the theoretical model are presented. Then, an analysis of the outcome under alternative institutions is conducted. Finally, a comparison of the institutions is undertaken to provide testable predictions for the empirical work.

As will be discussed in detail, the theoretical model will be designed to incorporate the procedures used in Italy. Specifically, the model will consider arbitration with one and three members and varying composition of the panels of three. Also, conventional arbitration, where the arbitrators are free to select any award they see fit, is considered. The setup, though, could be extended to model final-offer arbitration. 


\subsection{Preliminaries}

Suppose there are two parties, denoted $X$ and $Y$, involved in a dispute. Party $X$ is claiming that $Y$ has caused him damages and should be compensated. Let $d^{*}$ denote the "actual" or "true" damages incurred. To keep the analysis as simple as possible, assume $d^{*} \in\{0, D\}$ where $D>0$ and that $X$ and $Y$ both know the value of $d^{*}$ with certainty to abstract away from asymmetric information issues. The assumption that damages are either positive or zero is made for simplicity of the analysis. One could easily redefine $D$ as the difference in the (positive) damages. The testable predictions of the theoretical model would be unchanged. This would avoid concerns of credibility of threats and frivolous suits. ${ }^{6}$

There is also a set of potential arbitrators. Let $i$ denote an arbitrator. Each arbitrator observes a noisy signal of the true damages caused. Denote $d_{i}$ as arbitrator $i$ 's signal where $d_{i} \in$ $\{0, D\}$. Let the probability she receives a correct signal be denoted $p_{i}$, or rather, $\operatorname{Pr}\left(d_{i}=d^{*}\right)=p_{i}$. Hence, one may think of $p_{i}$ as capturing an arbitrator's accuracy. ${ }^{7}$ Assume $p_{i}>1 / 2 \forall i$. Also, assume $i$ 's accuracy is independent of the true state; $\operatorname{Pr}\left(d_{i}=d^{*} \mid d^{*}=D\right)=\operatorname{Pr}\left(d_{i}=d^{*} \mid d^{*}=0\right)$.

Depending on the institutional rules, the arbitrator(s) makes an award to Party $X$ as a result of the arbitration. Denote the reward as $R$. Costs are incurred by both sides. Denote $C^{x}$ and $C^{y}$ as the cost to arbitration. ${ }^{8}$ Assume both are risk-neutral. Alternatively, the parties to the dispute can privately reach an agreement without completing the arbitration process. Denote such a settlement as $S$. Reaching a settlement saves the cost of the arbitration procedure and, hence, may be viewed as socially preferable. The incentives to reach settlement, though, depend crucially on the institution employed, which is the issue we turn to next.

\footnotetext{
${ }^{6}$ If $d^{*} \in\left\{d_{L}, d_{H}\right\}$ where $d_{H}>d_{L}>0$, then from the upcoming derivations $R\left(d_{i}=d_{H}\right)=p_{i}\left(d_{H}-d_{L}\right)+d_{L}$ and $R\left(d_{i}=d_{H}\right)$ $=\left(1-p_{i}\right)\left(d_{H}-d_{L}\right)+d_{L}$. Defining $D=d_{H}-d_{L}$ (3) continues to hold. What is important for the analysis is that the arbitrators have an assessment over a range of possible states. The analysis can be extended to multiple states as well.

${ }^{7}$ The accuracy is best thought of as an exogenous characteristic of the arbitrator. We do not consider arbitrator learning as in Gibbons (1988).

${ }^{8}$ Initiating the arbitration procedure will, of course, involve significant costs. These, though, are sunk. Hence, it is best to think of $C^{x}$ and $C^{y}$ as the continuation (variable) costs that can be avoided.
} 


\subsection{Arbitration Institutions}

There are two scenarios to consider. In the first, the institutional rules require that only one arbitrator is selected to be involved with the settling of the dispute. In the second, the institution requires three to be selected. These two scenarios are not only the two employed in Italy, but also the two dominant forms around the world (Kirby, 2009).

Let $p^{x}\left(d^{*}\right)$ denote the accuracy of an arbitrator, as assessed by Party $X$, when the state is $d^{*}$. Similarly, let $p^{y}\left(d^{*}\right)$ denote this same probability, as assessed by Party $Y$. As is common in the literature on pretrial bargaining, we allow for divergent beliefs of the two parties in the dispute. Also, while the accuracy of the arbitration does not depend on the actual damages, we allow the beliefs of the parties regarding this accuracy to be state dependent. One may think of the disputants as suffering from optimism bias where $p^{x}(D)>p^{y}(D)$ and $p^{x}(0)<p^{y}(0){ }^{9}$

The tradition of optimistic beliefs in arbitration goes back to Farber and Bazerman (1989). For a discussion of uncertainty, differing expectations, and conflicts that arise in the selection of private adjudicators see Landes and Posner (1979).

\subsubsection{One Arbitrator}

If a sole arbitrator must make a decision in the case, then she uses her signal, since it is more likely to be accurate than not, in reaching her award decision. As stated, we model the arbitration as one of conventional arbitration where any outcome may be selected. With regards to the arbitrator's preferences assume the arbitrator has single-peaked preferences with her utility maximized at her assessed expected value of the damages caused. This is a common assumption when modeling jury decisionmaking for example (Friedman and Wickelgren, 2006; McCannon, 2010) and in formal models of arbitrator preferences (Farber, 1980; Gibbons, 1988; Klement and Neeman, 2013). Formally, define $R\left(d_{i}=D\right)=p_{i} D$ as the result she chooses if her signal is of a nonzero damage and $R\left(d_{i}=0\right)=\left(1-p_{i}\right) D$ as the result if her signal is of zero damages. Notice that under the assumption that $p_{i}>1 / 2, R(D)>R(0)$.

\footnotetext{
${ }^{9}$ While it is straightforward to present the environment as a behavioral one with heterogeneous beliefs, one could derive similar outcomes assuming asymmetric information. What is essential for the analysis is that there exist environments where pre-arbitration bargaining can fail so that an analysis of the bargaining zone can be conducted.
} 
The parties involved in the dispute, as stated, do not necessarily take $R\left(d^{*}\right)$ as the expected outcome of arbitration when negotiating over a settlement. Define $R^{t}(D)=p^{t}(D) D$ and $R^{t}(0)=\left[1-p^{t}(0)\right] D$ as the anticipated result for Party $t=X, Y$ when the actual damages are $d^{*}=D$ and $d^{*}=0$ respectively. Party $X$ believes, consequently, that he will receive $S$ with a settlement and $R^{x}\left(d^{*}\right)-C^{x}$ by continuing on with the arbitration process. He is willing to accept, then, any settlement where

$$
S \geq R^{x}\left(d^{*}\right)-C^{x}
$$

Similarly, Party $Y$ receives $-S$ if he settles and $-R^{y}\left(d^{*}\right)-C^{y}$ if the conflict continues until an arbitrator announces an award. Hence, he is unwilling to agree to any settlement unless

$$
S \leq R^{y}\left(d^{*}\right)+C^{y}
$$

Consequently, if both (1) and (2) hold, then a mutually-agreeable, private resolution exists to the conflict. Rather, if

$$
\begin{array}{ll}
{\left[p^{x}\left(d^{*}\right)-p^{y}\left(d^{*}\right)\right] D \leq C^{x}+C^{y}} & \text { when } d^{*}=D \\
\text { or } & \\
{\left[p^{y}\left(d^{*}\right)-p^{x}\left(d^{*}\right)\right] D \leq C^{x}+C^{y}} & \text { when } d^{*}=0,
\end{array}
$$

then a nonempty bargaining zone exists. ${ }^{10}$ Rather than formally modeling the bargaining game, we simply presume that if a bargaining zone exists, then the parties are able to obtain a settlement. We make this assumption, not because the mode of bargaining is unimportant, but rather than study the size of the award we are interested in the binary outcome of whether or not an agreement is reached. A similar tactic is employed by Farmer and Tiefenthaler (2001) analyzing the settlement of divorce disputes.

\footnotetext{
${ }^{10}$ This is an extremely common result in the economics of pretrial bargaining. See Deck and Farmer (2007) for a detailed discussion.
} 


\subsubsection{Three Arbitrators}

Consider the decisionmaking of a three-person panel. The issue arises as how to model conventional arbitration outcomes with a panel of arbitrators. As before, each arbitrator receives her signal of the state. Since it is assumed that for each arbitrator $p_{i}>1 / 2$, they prefer to follow that signal. To keep the analysis simple (and similar to that with one arbitrator) let $q$ denote the probability a majority of the arbitrators accurately identify the true damages, $d_{i}=d^{*}$ and prefer the award, under conventional arbitration, to be close to the expected value of the damages. Thus, the arbitrators can be expected to award $q D$ if $d^{*}=D$ and $(1-q) D$ if $d^{*}=0$. Hence, an analysis of $q$ allows us to compare the decisionmaking of a panel to that of a sole arbitrator and to contrast differing arrangements of the panel on arbitration outcomes and, consequently, bargaining.

Of course, bargaining does not necessarily depend on the accuracy of the arbitrators per se, but rather on the expected award, as assessed by the parties. As a first scenario to analyze, suppose the disputants are rather certain as to the accuracy of two of the arbitrators, but need to form an assessment of the third. This would occur if, for an example, two arbitrators are appointed by the parties, while the third is selected by the governing organization (as is the default in Milan). Let $z>1 / 2$ be the probability that each of the appointed arbitrators is accurate and maintain $p^{t}\left(d^{*}\right)$ as the assessed accuracy of the third arbitrator by Party $t$ in the state $d^{*}$. For simplicity, the assessments of the accuracy of the first two arbitrators are identical for each party. This assumption will later be relaxed. ${ }^{11}$

In this environment the probability of the majority of the arbitrators obtaining an accurate signal, $q^{t}\left(d^{*}\right)$, as assessed by Party $t$ in state $d^{*}$, can be derived. It follows that

$$
q^{t}\left(d^{*}\right)=z^{2}+2 p^{t}\left(d^{*}\right) z(1-z)
$$

As before, a bargaining zone exists if the expected award received by Party $X$, net of the costs, falls short of the award plus the costs, as assessed by Party $Y$, or rather,

\footnotetext{
${ }^{11}$ The state independence of $z$ is not crucial for the analysis. The results hold if $z\left(d^{*}=D\right)$ differs from $z\left(d^{*}=0\right)$.
} 


$$
\begin{array}{ll}
{\left[q^{x}(D)-q^{y}(D)\right] D \leq C^{x}+C^{y}} & \text { when } d^{*}=D \\
\text { or } & \\
{\left[q^{y}(0)-q^{x}(0)\right] D \leq C^{x}+C^{y}} & \text { when } d^{*}=0 .
\end{array}
$$

What we are interested in is the impact of adding arbitrators to the panel when there is uncertainty regarding the decisionmaking of an arbitrator. Consequently, one needs to assess whether the bargaining zone expands or contracts. As can be seen in (3) and (5), both the size of the bargaining zone along with the range of parameters in which it is nonempty depends on $p^{x}\left(d^{*}\right)-p^{y}\left(d^{*}\right)$ as compared to $q^{x}\left(d^{*}\right)-q^{y}\left(d^{*}\right)$. The following proposition provides the first result. All proofs are provided in the appendix.

Proposition 1: With optimistically-biased beliefs, $p^{x}(D)-p^{y}(D)>q^{x}(D)-q^{y}(D)>0$ and $p^{y}(0)-p^{x}(0)>q^{y}(0)-q^{x}(0)>0$.

Thus, the uncertainty of the arbitrator's decisionmaking allows for divergence in expected outcomes and facilitates a breakdown in bargaining. The effect of this uncertainty is dampened when other arbitrators are added to the process. This encourages a private resolution.

This result does not require the added arbitrators to have superior accuracy in their choices. The result requires that there are symmetric beliefs regarding the added arbitrators behaviors. Furthermore, it does not rely on symmetry in their accuracy. The proof could easily be extended to assuming $z_{1} \neq z_{2}$ for the two arbitrators. The crucial point is that divergent beliefs on an arbitrator are mitigated within a panel.

This result, though, depends upon agreement between the disputants over the accuracy of two of the arbitrators. Given that three panelists are employed, how does the outcome compare to the environment where there is uncertainty over more than one of the arbitrators? This would occur, for example, when a party is confident in its appointment, but unsure about the other two arbitrators.

Hence, to extend further the analysis let $r^{t}\left(d^{*}\right)$ denote the anticipated probability a majority receives a signal of $d_{i}=d^{*}$ as assessed by Party $t$ in state $d^{*}$ when $t$ is uncertain over two arbitrators. It follows that 


$$
r^{t}\left(d^{*}\right)=\left[p^{t}\left(d^{*}\right)\right]^{2}+2 z\left[1-p^{t}\left(d^{*}\right)\right] p^{t}\left(d^{*}\right)
$$

Hence, a bargaining zone exists if

$$
\begin{array}{ll}
{\left[r^{x}(D)-r^{y}(D)\right] D \leq C^{x}+C^{y}} & \text { when } d^{*}=D \\
\text { or } & \\
{\left[r^{y}(0)-r^{x}(0)\right] D \leq C^{x}+C^{y}} & \text { when } d^{*}=0 .
\end{array}
$$

When three arbitrators comprise a panel, how does uncertainty over one arbitrator compare to uncertainty over two? The following proposition provides the second result.

Proposition 2: With optimistically-biased beliefs, $r^{x}(D)-r^{y}(D)>q^{x}(D)-q^{y}(D)>0$ and $r^{y}(0)-r^{x}(0)>q^{y}(0)-q^{x}(0)>0$.

Thus, amongst the three-arbitrator panels, uncertainty over two arbitrators causes more continuances of the conflict than uncertainty over only one.

\subsection{Comparison of Institutions and Testable Predictions}

Thus, in this simple framework two testable hypotheses arise. First, it follows from Proposition 1 that amongst a set of contract disputes, those decided by a panel are more likely to be resolved. This is because the set of parameters under which a nonempty bargaining zone exists is greater. As is commonly argued, this makes the likelihood of resolution greater (Deck and Farmer, 2007).

Hypothesis 1: Disputes in which three arbitrators are selected are less likely to persist to a final arbitral decision than those disputes to be resolved by one arbitrator.

Furthermore, amongst cases to be decided by a panel, those where the divergence of beliefs applies to fewer arbitrators are more likely to be settled. This derives from Proposition 2 that 
divergent beliefs on two arbitrators is less likely to have a nonempty bargaining than divergent beliefs on only on arbitrator.

Hypothesis 2: Disputes where the parties have non-divergent beliefs regarding the accuracy of at least two of the three arbitrators are less likely to persist to a final arbitral decision than disputes with only one arbitrator with non-divergent beliefs.

Empirical data of contract disputes with differing compositions of arbitration panels with differing numbers of arbitrators can be exploited to test these two hypotheses.

\section{Background Information and Data}

Contracts of Italian firms typically include a clause describing how disputes that arise will be dealt with. This clause is referred to as the Clausola Compromissoria. This clause describes the arbitration process to be used. The Italian civil code defining procedures for the Clausola (the Codice di Procedura Civile, §808) requires that such clauses either identify the name(s) of the individual(s) who will serve as an arbitrator if a dispute arises or specify the number of arbitrators to be used along with the procedure under which they are selected (Carpi and Taruffo, 2008). Thus, the institutional features of the arbitration process are determined before a conflict arises and are, therefore, exogenous to the dispute. For contract disputes that arise in Italy, the arbitration procedures are selected "behind the veil of ignorance" (Rawls, 1971).

The Chamber of Commerce in Milan, known as the Camera di Commercio, has developed an arbitration council to facilitate the resolution of disputes through arbitration. The council is called the Camera Arbitrale Milano. Most Italian firms have coordinated on employing the use of the Camera in the clauses of their contracts. This includes not only Italian 
firms operating in Milan, but also Italian firms throughout the country contracting with other Italian firms and even in contracts with other European and international organizations.

The Camera Arbitrale Milano publishes it rules governing the arbitration process respecting the previously contracted upon terms and providing the institutional features to be employed when the clause is incomplete (Arbitration Rules, 2011). The rules outline the important procedural issues such as the mechanism for submitting documents, use of expert witnesses, and timing of the steps of the process to name a few.

With regards to the selection and number of arbitrators the Camera's rules allow for the contracted upon structure to remain. Unless otherwise agreed upon in the clause, if a sole arbitrator is to be used the Camera will appoint one. If the parties agree beforehand to use a council of three arbitrators, the Arbitration Rules stipulate that the default selection procedure is for each party to the dispute to unilaterally select their own arbitrator. The third arbitrator, who will also act as the panel's president, will be appointed by the Camera. The clause may contain a provision, though, for the two selected arbitrators to pick the third. In this case, the Camera makes an appointment if the two arbitrators cannot reach a consensus within a predetermined time limit.

As a consequence, at the time of initiating the dispute the institutional structure of the arbitration process is known, i.e. whether one or three arbitrators is to be used and how the arbitrators will be selected, but the identity of the panel is not known. ${ }^{12}$ Once the arbitrators are selected, and they agree to serve, the collecting of documents and the holding of the hearings commence. After the determination of the arbitrators, but before the announcement of the arbitral award, the parties are free to withdraw their claims. The withdrawal can arise from a settlement

\footnotetext{
${ }^{12}$ A party may know his selection and, also, it is possible to know the identity of the other party's selected arbitrator (since the identities may be contracted upon), but he is unlikely to be able to anticipate the identity of the entire panel.
} 
being struck between the two parties or "other grounds" (i.e. withdrawing a claim due to a lack of supporting evidence).

Regarding the costs associated with the arbitration, initial filing fees are required. The Camera determines the size of the total fees as a function of number of arbitrators used, amount of evidence processed, etc. If a claim is withdrawn, though, a reduced final cost is due. Thus, settlement during the arbitration process provides the added benefit of further reducing costs.

It is this choice to settle during the negotiation, after the information regarding the identity of the arbitrators and providing the opportunity to reduce expenses, that allows one to identify how the structure of the institution affects bargaining. The distinction between the benefit and motivation of ex ante ADR agreements, as explored here, and ex post ADR (the decision to utilize arbitration and other dispute resolution institutions made after the conflict arises) is discussed by Shavell (1995).

The main source of data for the empirical analysis is the recorded information of disputes brought to the chamber in Milan, Camera Arbitrale Milano, from January 2007 to end of first quarter of 2010. The content of all arbitration cases filed and in the period under review was analyzed in June 2011 using a coding protocol developed by the authors. Over this period, by the time of the data collection, a total of 391 disputes were filed since the beginning of our investigation and had been completed either with an arbitral award or with settlement (and, hence, withdrawn from the Camera).

Information from the records of each dispute was collected. The variables of interest for this study, together with their definition and descriptive statistics, are set out in Table 1 and Table 3. Five dummy variables are created. The variable award is equal to one if the case was concluded with the arbitrator(s) announcing an award. A value of award of zero indicates a 
withdrawal of the case due to a settlement being reached. This is the dependent variable in the econometric analysis.

To test Hypothesis 1, the variable panel is equal to one if a panel of three arbitrators was used in the dispute. A value of zero indicates that only one arbitrator was selected. The Rules of Arbitration (2011) prohibit the use of an even number of arbitrators, presumably due to the use of majority voting within the panel, and there were not any recorded circumstances of a panel exceeding three.

Third, information on the occupation of the arbitrators is provided. Arbitrators used in Milan are either privately-practicing lawyers or university professors, typically law professors. If a majority of the arbitrators used in a case hold an academic position, then the dummy variable prof equals one. We argue that prof can be used to test Hypothesis 2. Law professors have public track records of service and scholarship. Furthermore, it is common for university faculty to repeatedly serve as arbitrators. This is important because information of previous decisions may be known, i.e. so that there is a reputation, and they have the incentive to do a good job so as to be selected in the future i.e., so that they have reputational concerns. Furthermore, practicing attorneys could have professional concerns that make their decisionmaking uncertain from the perspective of the disputants. Finally, as obtaining a faculty position acts as a quality screening mechanism, more certainty may arise of those who can acquire such jobs. See Klement and Neeman (2013) for an extended discussion of arbitrator incentives. For these reasons we hypothesize that having multiple professors on the panel corresponds with less-divergence of the beliefs of the disputants. Consequently, support for Hypothesis 2 will arise if prof $=1$ is associated with a decreased likelihood of award $=1$. 
If the president of the panel was appointed by the disputants, then appoint $=1$. Within a panel of three arbitrators, typically each party makes a selection, and these individuals then select the third member to act as the chair. If the selected arbitrators cannot reach an agreement, or if the initial clause in the contract does not specify this procedure, then the third arbitrator is selected by the Camera. In the case of a sole arbitrator again the default rules indicate that she is selected by the chamber (so that appoint $=0$ ).

The final dummy variable created from the case files is a measurement of the legal representation of the parties. The lawyer representing the claimant along with the name of the law firm under which he is employed is provided. The coding protocol used was to differentiate those disputes where the legal representation was provided by a member of a "big" law firm from those coming from a small practice. In the Italian legal community the identity of the largescale law firms, employing numerous lawyers and staff, is well known. ${ }^{13}$ Thus, the variable lawfirm captures this distinction. The legal representation of the party not initiating the dispute is not included. One reason for this is that the information is not available for many cases since it is the claimant's lawyer who files the initial paperwork. Also, when it is available it is highly correlated with the choice of legal representation of the claimant. This is to be expected. Ashenfelter and Dahl (2012) and Ashenfelter, Bloom and Dahl (2013) argue, for example, that the hiring of legal representation is a prisoner's dilemma situation where both parties are in an arms race expending resources on more and expensive lawyers. Data from arbitration in New Jersey provides confirmation.

In addition to these dummy variables, two other independent variables are created. The first, hearings, captures the activity level of each dispute by quantifying the number of hearings

\footnotetext{
${ }^{13}$ An Italian legal scholar with expertise in the civil procedure of Italy, and himself an occasional arbitrator, was consulted to create and verify the list of "big" law firms. Given the high statistical significance of this variable illustrated in the upcoming section, we are confident in the validity of our coding.
} 
and the variable, documents, measures the number of technical reports, evidentiary statements, and other relevant documentations submitted. One would expect these to be correlated with the complexity of the case and, hence, be associated with continued conflict.

Table 1: Descriptive Statistics

\begin{tabular}{lllll}
\hline \hline variable & description & & & \\
& & \# of obs. & mean & st. dev. \\
\hline & & & & \\
award & $=1$ if the arbitrator(s) made an award & 391 & 0.491 & 0.501 \\
panel & $=1$ if three arbitrators used & 389 & 0.666 & 0.472 \\
prof & $=1$ if majority are professors & 391 & 0.455 & 0.498 \\
appoint & $=1$ if president is selected by the parties & 391 & 0.169 & 0.375 \\
lawfirm & $=1$ if claimant's attorney from big law firm 389 & 0.141 & 0.349 \\
hearings & \# of hearings & 314 & 2.379 & 1.992 \\
documents & \# of documents submitted & 378 & 6.389 & 5.079
\end{tabular}

As one can see, twice as many disputes in Milan's chamber of commerce utilize three arbitrators as those with only one, while the cases are split between private resolution and continuation of the process to an awarding stage. The parties to the dispute select the panel president in less than one-sixth of the disputes. Thus, the Camera Arbitrale Milano must frequently make the selections. Interestingly, the number hearings conducted and documents submitted exhibit large standard deviations relative to their mean values. Thus, there is a lot of heterogeneity in the degree of conflict and the stakes of the disputes. Finally, while a total of 391 disputes were resolved over the time period, not every case file provided complete information. Thus, some variables suffer from missing values (third column of Table 1). For example, hearings is available for $85.4 \%$ of the cases $(=314 / 391)$.

The two hypotheses arising from the theoretical model predict that panel and prof affect the ability to reach a settlement, award. Table 2 provides initial evidence of the differentiation between the arbitration disputes that result in a final decision and those where private settlements occurred. 
Table 2: Arbitrator Panels

\begin{tabular}{lllll}
\hline \hline & $\begin{array}{l}\text { award }=1 \\
\text { \# of obs. }\end{array}$ & $\%$ & $\begin{array}{l}\text { award }=0 \\
\text { \# of obs. }\end{array}$ & $\%$ \\
\hline panel $=1$ & 108 & $27.8 \%$ & 151 & $38.8 \%$ \\
panel $=0$ & 84 & $21.6 \%$ & 46 & $11.8 \%$ \\
prof $=1$ & 85 & $21.7 \%$ & 93 & $23.8 \%$ \\
prof $=0$ & 107 & $27.4 \%$ & 106 & $27.1 \%$
\end{tabular}

For those cases with three arbitrators there are almost $40 \%$ more cases that do not reach a final award than do. Interestingly, disputes with only one arbitrator do not reach an arbitral award occurring with a frequency $45 \%$ less than disputes involving a three arbitrator panel. This suggests that there is a relationship between the two lending support for Hypothesis 1. Similarly, while outcomes are rather evenly split when university professors are not involved; when they are involved there is a decrease in the relative rate at which disputes persist until a final award. Again, this is suggestive of an influence of professors on settlements, as predicted by Hypothesis 2.

Disputes arise from a number of types of contracts. The data available allow us to control for a broad number of categories based on the content of the case. ${ }^{14}$ Table 3 presents these categorizations along with some basic descriptive information.

\footnotetext{
${ }^{14}$ Again, expertise in Italian law was consulted. To clarify the sale of business category includes any transfer of ownership of a business or franchise agreement, while joint ventures are treated separately. Contracts regarding the distribution of goods are separating from both contracts on the sales of goods as well as contracts on the supplies of inputs. Governance relates to disputes regarding shareholders, boards, and executive management. Procurement disputes differ from supply contracts in that only in the latter is a signed contract between the buyer and seller of a single good exist. Procurements include contracts for bundles of services.
} 


\begin{tabular}{|c|c|c|c|c|}
\hline \multirow[b]{2}{*}{ content } & \multirow[b]{2}{*}{ \# of obs. } & \multicolumn{3}{|c|}{$\%$ of obs. within each content area with... } \\
\hline & & award $=1$ & panel $=1$ & lawfirm $=1$ \\
\hline company law & 136 & $58 \%$ & $76 \%$ & $22 \%$ \\
\hline procurement & 65 & $29 \%$ & $75 \%$ & $6 \%$ \\
\hline commercial distribution & 36 & $69 \%$ & $42 \%$ & $8 \%$ \\
\hline commercial sale & 22 & $50 \%$ & $62 \%$ & $10 \%$ \\
\hline sale of business & 21 & $24 \%$ & $48 \%$ & $10 \%$ \\
\hline supply contract & 22 & $41 \%$ & $55 \%$ & $14 \%$ \\
\hline consulting & 13 & $69 \%$ & $54 \%$ & $0 \%$ \\
\hline trademarks/patents & 10 & $50 \%$ & $60 \%$ & $40 \%$ \\
\hline joint venture & 6 & $67 \%$ & $0 \%$ & $0 \%$ \\
\hline insurance & 4 & $50 \%$ & $100 \%$ & $25 \%$ \\
\hline other & 56 & $43 \%$ & $73 \%$ & $11 \%$ \\
\hline
\end{tabular}

The chamber in Milan arbitrates a wide variety of cases. Each type of case differs in the persistence of conflict, construction of the arbitration panel, and legal representation. Controlling for case content will, then, be imperative.

\section{Results}

Thus, data from arbitration filings in Milan of contract disputes is used to test the two hypotheses derived from the theoretical model. To do this, logistic regressions are estimated with the binary variable, award, as the dependent variable. Controls for the content of the cases along with information regarding the institutional arrangement are included. Table 4 presents the results. 
Table 4: Logistic Results

$($ dep. var. $=$ award $)$

\begin{tabular}{|c|c|c|c|c|}
\hline & I & II & III & IV \\
\hline panel & $\begin{array}{l}0.357 * * * \\
(0.088)\end{array}$ & $\begin{array}{l}0.244 * * * \\
(0.093)\end{array}$ & $\begin{array}{l}0.222 * * * \\
(0.082)\end{array}$ & $\begin{array}{l}0.251 * * * \\
(0.014)\end{array}$ \\
\hline hearings & & $\begin{array}{l}1.562 * * * \\
(0.190)\end{array}$ & $\begin{array}{l}1.564 * * * \\
(0.190)\end{array}$ & $\begin{array}{l}1.580 * * * \\
(0.194)\end{array}$ \\
\hline documents & & $\begin{array}{l}1.243 * * * \\
(0.059)\end{array}$ & $\begin{array}{l}1.252 * * * \\
(0.060)\end{array}$ & $\begin{array}{l}1.251 * * * \\
(0.060)\end{array}$ \\
\hline lawfirm & & $\begin{array}{l}0.352 * * \\
(0.165)\end{array}$ & $\begin{array}{l}0.360 * * * \\
(0.169)\end{array}$ & $\begin{array}{l}0.381 * * \\
(0.180)\end{array}$ \\
\hline appoint & & $\begin{array}{l}0.475 * \\
(0.01)\end{array}$ & & $\begin{array}{l}0.586 \\
(0.257)\end{array}$ \\
\hline prof & & & $\begin{array}{l}0.514 * * \\
(0.166)\end{array}$ & $\begin{array}{l}0.586 \\
(0.199)\end{array}$ \\
\hline content? & YES & YES & YES & YES \\
\hline$N$ & 389 & 309 & 309 & 309 \\
\hline Pseudo- $\mathrm{R}^{2}$ & 0.091 & 0.331 & 0.333 & 0.396 \\
\hline$\%$ correct & $64.0 \%$ & $77.7 \%$ & $78.3 \%$ & $79.0 \%$ \\
\hline
\end{tabular}

Column I provides evidence is support of Hypothesis 1 that a three-person panel of arbitrators facilitates private resolutions. A case, controlling for the types of contracts being disputed, is only $35.7 \%$ as likely to continue to a final decision if a panel is utilized, as compared to using only a single arbitrator.

The specification in Column II adds additional control variables. Conflicts that involve more hearings with more documentation are associated with situations where private resolutions 
fail. If legal representation from a big law firm is utilized, then there is a decreased likelihood of continued conflict. This is in line with previous research on the value of legal representation in litigation (Farmer and Tiefenthaler, 2001).

While the statistical significance of panel remains, the results in Column II suggest that an appointment of the chair by the parties to the dispute increases private settlements. This result is to be expected since agreement on the selection of the panel president is likely correlated with the ability to reach an agreement to the dispute. The insignificance of the coefficient on appoint in Column IV suggests that university faculty members are often the one's being appointed by the parties so that it is unclear whether it is the confidence in the professors or the agreement on the third arbitrator that facilitates settlement. Evidence of this multicollinearity exists. The correlation between appoint and prof is 0.38 ( $\mathrm{p}$-value $<0.01$ ).

The results in Column III indicate that if at least a majority of the arbitrators are university professors, then it is unlikely that the case will proceed to a final arbitral award. This variable too loses significance in the final column. It is worth pointing out that the results in Table 4 pool all cases, whether they involve one arbitrator or three, into one data set. Given that each specification controls for the size of the panel, the coefficient on prof measures the marginal effect of a university professor when only one arbitrator is being used. The results from the theoretical model specifically predict that amongst the three-arbitrator panels, the employment of individuals with more certain and less divergent beliefs facilitates private settlement (Hypothesis 2). To address this question two approaches are utilized and reported in Table 5. First, an interaction term between panel and prof is included to differentiate the impact of university professors in the two settings. Second, the subsample of cases with three arbitrators utilized is considered separately. Again, in each specification controls for the content of the dispute are included. 
Table 5: Additional Results

(dep. var. = award)

\section{Interaction Panel Subsample}

\begin{tabular}{|c|c|c|}
\hline panel & $\begin{array}{l}0.378 * * \\
(0.165)\end{array}$ & \\
\hline hearings & $\begin{array}{l}1.582 * * * \\
(0.191)\end{array}$ & $\begin{array}{l}1.542 * * * \\
(0.227)\end{array}$ \\
\hline documents & $\begin{array}{l}1.250 * * * \\
(0.059)\end{array}$ & $\begin{array}{l}1.267 * * * \\
(0.074)\end{array}$ \\
\hline lawfirm & $\begin{array}{l}0.372 * * \\
(0.177)\end{array}$ & $\begin{array}{l}0.330 * * \\
(0.164)\end{array}$ \\
\hline prof & $\begin{array}{l}1.532 \\
(0.953)\end{array}$ & $\begin{array}{l}0.333 * * * \\
(0.135)\end{array}$ \\
\hline panel $\mathrm{x}$ prof & $\begin{array}{l}0.214 * * \\
(0.156)\end{array}$ & \\
\hline $\begin{array}{l}\text { content? } \\
N \\
\text { Pseudo- }{ }^{2} \\
\% \text { correct }\end{array}$ & $\begin{array}{l}\text { YES } \\
309 \\
0.345 \\
78.3 \%\end{array}$ & $\begin{array}{l}\text { YES } \\
194 \\
0.304 \\
77.3 \%\end{array}$ \\
\hline & $\begin{array}{l}10 \% \text { level; } \\
\text { Each specific: }\end{array}$ & \\
\hline
\end{tabular}

The results in Table 5 provide evidence in support of the second hypothesis arising from the theoretical model. University law professors have much publicly available information and reputational considerations matter. Consequently, there should be less divergence of the beliefs of the disputants when law professors make up the majority of the panel. In these cases, the chance of a conflict continuing all the way to an arbitral decision is only $21.4-33.3 \%$ as likely.

As a final issue to consider, one may be concerned with potential endogeneity problems with the selection of contract clauses. While the clause is written without knowing the nature of 
the dispute, one may worry that a party can anticipate the type of dispute that might arise and select the arbitration mechanism that is most appropriate. To address this concern we analyze bivariate probit models where the auxiliary equation uses as a dependent variable whether a panel of three arbitrators is employed. ${ }^{15}$ The sum of the log-likelihoods from the comparison models is -282.9 , while for the full model it is -282.8 . A Wald Test of potential correlation of the residuals fails to find any. Thus, endogeneity does not affect the validity of our results.

Furthermore, the same concerns can be raised with the other emphasized explanatory variable, prof. In disputes where the arbitration process utilizes three panelists and the clause allows for each party to select an arbitrator, the utilization of university faculty is a choice variable. A bivariate probit analysis provides mixed results and, therefore, we are unable to rule out with sufficient certainty whether endogeneity problems arise with this variable. These bivariate probit results are presented in the appendix.

\section{The Costs of Arbitration}

The theoretical model presented argues that uncertainty is the driving force behind the failure to reach a successful bargaining outcome. Thus, institutional features, such as panels and background information on decision makers, facilitate negotiations in the shadow of arbitration. The source of the uncertainty is divergent beliefs by the parties to the negotiation. Along with the degree of divergence in beliefs, the size of the cost to arbitration also determines the size of the bargaining zone.

It seems reasonable that the costs to completing the arbitration with a panel of three arbitrators are greater than having only one arbitrator. An alternative argument, then, is that the escalated costs that come with a panel of arbitrators facilitates bargaining. Since the costs are greater, the parties are motivated to settle and avoid the

\footnotetext{
${ }^{15}$ Two models were considered. One estimation considers panel with one less variable than the primary model the second estimation added a dummy variable clause to replace it. The variable clause is equal to one if the clause specifying the use of arbitration in Milan was included in the original contract. Both specifications provide results that strongly suggest no correlation between the errors.
} 
additional expenses. As a consequence, the costs to arbitration could be an alternative explanation for the empirical result presented in the previous section.

There is evidence, though, that it is the uncertainty, and not just the cost differences, that are contributing to the results. First, the rules of the Camera Arbitrale Milano have the arbitrators determine the allocation of costs as part of their final decision. ${ }^{16}$ Thus, avoiding the costs is part of the award. Therefore, the expected cost to seeing the dispute through to an arbitral award could reasonably be estimated by a disputant as $(1-p) C$. With optimistic beliefs, for example, the assessed cost to arbitration is small. Thus, cost differences are not as great.

Alternatively, while costs could explain the positive and statistically significant coefficient to panel, they are unable to account for the effect of university law faculty, which is our alternative measurement of uncertainty. The fees paid to arbitrators are not differentiated based on profession.

Further evidence exists that supports the argument that it is the care, effort, expertise, and reputation of the arbitrators that helps mitigate uncertainty. When university law faculty make up at least a majority of the panel of arbitrators more documents and hearings occur. The mean number of documents collected is 7.6 , while if law faculty are not used it is only 5.5. The correlation coefficient between documents and prof is positive and statistically significant at the $5 \%$ level. The mean number of hearings is $12 \%$ higher when university law faculty are used as well. Similarly, panels of arbitrators review more documents and have more hearings than single arbitrator cases (the mean is $1.3 \%$ and $11.9 \%$ higher, respectively). Therefore, along with their reputation, the intensity of investigation can be argued to facilitate bargaining, which supports our contention that costs alone are not driving the empirical results.

\footnotetext{
${ }^{16}$ More precisely, as stated in art. 36 of the CAM Rules, with regard to the costs of the proceedings, "1. The Arbitral Council shall determine the costs of the arbitration before the award is filed. 2. The Arbitral Council shall inform the Arbitral Tribunal and the parties of its determination of the costs which the Arbitral Tribunal shall indicate in the award. The determination of the Arbitral Council shall not affect the decision of the Arbitration Tribunal as to the allocation of the cost to the parties."
} 
The consideration of cost, though, does highlight an important institutional design tradeoff. Alternative dispute resolution frameworks are employed to reduce expenditures. If the primary expense is the fees paid to the arbitrators, then single arbitration mechanisms should be better as aggregate costs are reduced. Our results indicate that panels, which facilitate private resolution, can save the costs of prolonged conflict. This reduces not only the monetary expenditures, but saves the opportunity cost of the time devoted by the two parties. The net effect is unclear. A full welfare analysis is needed to identify optimal institutional rules.

In a related study by Marselli, Scano and Vannini (2015) the length of time devoted to the arbitration dispute is considered. They find that the panels take more days to complete. ${ }^{17}$ While the analysis does not control for the specific evidence and type of each dispute, it is suggestive that the net effect could be increased costs with panels of arbitrators. Therefore, both uncertainty and cost are key considerations in arbitration.

\section{Conclusion}

A wide variety of institutional arrangements exist for the arbitration of disputes. While previous research has focused on the distinction between conventional and final-offer arbitration, we investigate the use of panels and the composition of the panel and their identity. A theoretical model merging the impact of uncertainty in bargaining with the accuracy of group decisionmaking is developed to provide empirically testable predictions. Data from disputes in Milan, Italy is utilized to conduct these tests. Our main finding is that panels of arbitrators allow for the muting of uncertainties over the quality of the decisionmaking in arbitration. While this result is simply an application of the Condorcet Jury Theorem, we are able to show that this mitigation facilitates settlements and private resolutions to the conflicts. Furthermore, if it is possible to further reduce uncertainty by providing better information on the arbitrators, such as

\footnotetext{
${ }^{17}$ Estimating an unconditional Kaplan-Meier survival function they find that the average length is 410 days when the dispute is brought in front of a panel, while it is just 320 days when the dispute involves only one arbitrator.
} 
utilizing university professors with reputations and public records, even more settlements can be encouraged.

We are able to provide these empirical results due to the exogenous variation in institutional arrangements utilized in Italy. Since arbitration clauses are not standardized, yet agreed upon at the creation of the contract, the dispute if it does arise is independent of the institution used. Hence, the connection between institutional arrangements and bargaining success can be explored. Disputes arise and the arbitration process is initiated. This results in the selection of the arbitrators. In situations where uncertainty is now mitigated, bargaining is successful and the case is withdrawn. In circumstances where the selection of the arbitrators does not sufficiently reduce uncertainty, conflict persists. Consequently, the impact of institutional design on bargaining should be a consideration when engaging in mechanism design.

One can reasonably be concerned that selection effects may be driving the results. Bivariate probit analysis reveals that the choice of panel size is not correlated with dispute resolution. In many circumstances, though, the parties select arbitrators after the conflict has arisen and, hence, we cannot be sure that the selection of university professors is exogenous to the factors driving the disputes. Bivariate probit analysis suggests that it is not an issue, but, ultimately, gives mixed results. Another consideration is that it is reasonable to assume that more complex cases are less likely to settle, but also more likely to employ higher quality arbitrators, such as law professors, as employ panels. Thus, the selection effect may be working in the opposite direction as the results presented in the text; strengthening the arguments presented. Regardless, the results presented in the text strongly suggest that the identity of the arbitrators affects disputant certainty and, consequently, settlement.

Similarly, our theoretical model of uncertainty in bargaining is used to derive testable predictions to put to the data. One could imagine additional factors, not considered, that can drive settlement. Examples include asymmetric information, cost, and risk preferences. We are unable to rule out alternative, theoretical frameworks. What is important is the result that panel size and arbitrator characteristics affect the ability of parties to a dispute to reach a private settlement and that these empirical results are consistent with a theory that uncertainty, and its mitigation, affects bargaining.

The analysis focuses on settlement, acknowledging that conflict is costly. Thus, private resolution increases the well-being of both parties and reduces resource use. We are unable to 
address the distribution of the surplus created/saved (i.e. wealth effects). Similarly, the deterrence of the contract breaches is not considered (Drahozal and Hylton, 2003). Furthermore, we use the crude proxy of the number of university professors to measure uncertainty. More detailed knowledge on the backgrounds of the arbitrators and particulars of the dispute may be necessary to design improved mechanisms. For example, Baye and Wright (2011) provide

evidence that U.S. Federal judges with additional training in economics are well-suited to preside over antitrust cases as their decisions are appealed at lower rates. Future work on these issues should help craft improved arbitration processes saving time and resources.

\section{References}

Ashenfelter, O., Bloom, D.E., 1984. Models of arbitrator behavior: Theory and evidence. American Economic Review 74, 111-124

Ashenfelter, O.E., Bloom, D.C., Dahl, G.B., 2013. Lawyers as agents of the devil in a prisoner's dilemma game: Evidence from long run play. NBER Working Paper Series No. 18834

Ashenfelter, O,E., Dahl, G.B., 2012. Bargaining and the role of expert agents: An empirical study of final-offer arbitration. Review of Economics and Statistics 94, 116-132

Baye, M.R., Wright, J.D., 2011. Is antitrust too complicated for generalist judges? The impact of economic complexity and judicial training on appeals. Journal of Law and Economics 54, 1-24

Bernstein, L., 1992. Opting out of the legal system: Extralegal contractual relations in the diamond industry. Journal of Legal Studies 21, 115-157

Camera Arbitrale Milano, 2011. Arbitration rules. www.camera-arbitrale.com

Carpi, F., Taruffo, M., 2008. Commentario breve al codice di procedura civile. CEDAM, Padua 
Crawford, V.P., 1979. On compulsory-arbitration schemes. Journal of Political Economy 87, 131-159

Crawford, V.P., 1982. Compulsory arbitration, arbitral risk and negotiated settlements: A case study in bargaining under imperfect information. Review of Economic Studies 49, 69-82

Cooter, R., Marks, S., Mnookin, R., 1982. Bargaining in the shadow of the law: A testable model of strategic behavior, Journal of Legal Studies 11, 225-251

Currie, J., McConnell, S., 1994. The impact of collective-bargaining on disputes in the U.S. public sector: No legislation may be worst legislation. Journal of Law and Economics 37, 519547

Dari-Mattiacci, G., 2007. Arbitration versus settlement. Revue Èconomique 50, 1291-1308

Deck, C.A., Farmer, A., 2007. Bargaining over an uncertain value: Arbitration mechanisms compared. Journal of Law, Economics \& Organization 23, 547-579

Deck, C.A., Farmer, A., 2009. Strategic bidding and investments in final offer arbitration: theory and experimental evidence. Journal of Economic Behavior \& Organization 70, 361-373

Drahozal, C.R., Hylton, K.N., 2003. The economics of litigation and arbitration: An application to franchise contracts. Journal of Legal Studies 32, 549-584

Farber, Henry S., 1980. An analysis of final-offer arbitration. Journal of Conflict Resolution 24, 683-705

Farber, H.S., Bazerman, M.H., 1986. The general basis of arbitrator behavior: An empirical analysis of conventional and final-offer arbitration. Econometrica 54, 819-844 
Farber, H.S., Bazerman, M.H., 1989. Divergent expectations as a cause of disagreement in bargaining: Evidence from a comparison of arbitration schemes. Quarterly Journal of Economics 104, 99-120

Farmer Curry, A., Pecorino, P., 1993. The use of final offer arbitration as a screening device. Journal of Conflict Resolution 37, 655-669

Farmer, A., Pecorino, P., 1998. Bargaining with informative offers: An analysis of final-offer arbitration. Journal of Legal Studies 27, 415-432

Farmer, A., Pecorino, P., 2003. Bargaining with Voluntary Transmission of Private Information: Does the use of final offer arbitration impede Settlement? Journal of Law, Economics \& Organization 19, 64-82

Farmer, A., Pecorino, P., Stango, V., 2004.The causes of bargaining failure: Evidence from Major League Baseball. Journal of Law and Economics 47, 543-568

Farmer, A., Tiefenthaler, J., 2001. Conflict in divorce disputes: The determinants of pretrial settlement. International Review of Law and Economics 21, 157-180

Friedman, E., Wickelgren, A.L., 2006. Bayesian juries and the limits to deterrence. Journal of Law, Economics, \& Organization 22, 70-86

Gibbons, R., 1988. Learning in equilibrium models of arbitration. American Economic Review $78,896-912$

Kirby, J., 2009. With arbitrators, less can be more: Why the conventional wisdom on the benefits of having three arbitrators may be overrated, Journal of International Arbitration 26, 337-355

Klement, A., Neeman, Z., 2013. Win/loss ratios improve their accuracy? Journal of Legal Studies 42, 369-397 
Landes, W.M., Posner, R.A., 1979. Adjudication as a private good. Journal of Legal Studies 8, 235-284

Lederman, L., 1999. Which cases go to trial?: An empirical study of predictions of failure to settle. Case Western Law Review 49, 315-358

Marselli, R., Scano, A., Vannini, M., 2015. L'arbitrato alla prova dei dati: un'analisi empirica sugli arbitrati amministrati dalla Camera Arbitrale di Milano. Rivista Trimestrale di Diritto e Procedura Civile (forthcoming)

McCannon, B.C., 2010. The median juror and the trial of Socrates. European Journal of Political Economy 26, 533-540

McCannon, B.C., 2011. Jury size in Classical Athens: An application of the Condorcet Jury Theorem. Kyklos 64, 106-121

McCannon, B.C., 2015. Condorcet Jury Theorems. forthcoming, Handbook of Social Choice and Voting, Cheltenham, UK: Elgar Publishing

McMillan, J., Woodruff, C., 1999. Dispute prevention without courts in Vietnam. Journal of Law, Economics \& Organization 15, 637-658

Mueller, D.C., 2003. Public choice III, Cambridge: Cambridge University Press.

Rawls, J., 1953. A theory of justice, Oxford: Oxford University Press.

Shavell, S., 1995. Alternative dispute resolution: An economic analysis. Journal of Legal Studies 24(1), 1-28 
Speight, A., Thomas, D., 1997. Arbitrator decision-making in the transfer market: An empirical analysis. Scottish Journal of Political Economy 44, 198-215

Spurr, S.J., 2000. The role of nonbinding alternative dispute resolution in litigation. Journal of Economic Behavior \& Organization 42, 75-96

Van Boening, M., Pecorino, P., 2001. Bargaining and information: An empirical analysis of a multistage arbitration game. Journal of Labor Economics 19, 922-948

Van Boening, M., Pecorino, P., 2004. An empirical analysis of bargaining with voluntary transmission of private information. Journal of Legal Studies 33, 131-156

Young, H.P., 1988. Condorcet's theory of voting. American Political Science Review 82, 1231 1244

\section{Appendix}

The Appendix provides additional work not presented in the text. First, the formal proofs of the propositions stated in the paper are given.

Proof of Proposition 1: Suppose $d^{*}=D$. It follows from (4) that $q^{x}(D)-q^{y}(D)=z^{2}+2 p^{x}(D) z(1$ $-z)-z^{2}-2 p^{y}(D) z(1-z)=2 z(1-z)\left\{p^{x}(D)-p^{y}(D)\right\}$. Since $z \in(0,1), 2 z(1-z)<1$. Optimism bias implies $p^{x}(D)-p^{y}(D)$. Hence, $p^{x}(D)-p^{y}(D)>q^{x}(D)-q^{y}(D)>0$. Suppose $d^{*}=0$. It follows from (4) that $q^{y}(0)-q^{x}(0)=2 z(1-z)\left\{p^{y}(0)-p^{x}(0)\right\}$. Optimism bias implies $p^{y}(0)>p^{x}(0)$. Hence, $p^{y}(0)-p^{x}(0)>q^{y}(0)-q^{x}(0)>0$.

Proof of Proposition 2: Suppose $d^{*}=D$. It follows from (6) that $r^{x}(D)-r^{y}(D)=\left[p^{x}(D)\right]^{2}+$ $2 z p^{x}(D)\left[1-p^{y}(D)\right]-\left[p^{x}(D)\right]^{2}-2 z p^{y}(D)\left[1-p^{y}(D)\right]=\left\{\left[p^{x}(D)\right]^{2}-\left[p^{y}(D)\right]^{2}\right\}(1-2 z)+2 z\left[p^{x}(D)-\right.$ $\left.p^{y}(D)\right]$. It follows from (4) that $q^{x}(D)-q^{y}(D)=2 z\left[p^{x}(D)-p^{y}(D)\right]-2 z^{2}\left[p^{x}(D)-p^{y}(D)\right]$. 
Consequently, $r^{x}(D)-r^{y}(D)$ is greater than $q^{x}(D)-q^{y}(D)$ when $\left\{\left[p^{x}(D)\right]^{2}-\left[p^{y}(D)\right]^{2}\right\}(2 z-1)<$ $2 z^{2}\left[p^{x}(D)-p^{y}(D)\right]$. This simplifies to require $\left[p^{x}(D)+p^{y}(D)\right]<2 z^{2} /[2 z-1]$. Notice that the right-hand-side, $R(z)=2 z^{2} /[2 z-1]$, is decreasing in $z$ and $R(1)=2$. Since $p^{x}(D)+p^{y}(D)<2$, $r^{x}(D)-r^{y}(D)>q^{x}(D)-q^{y}(D)$. Similarly, $r^{y}(0)-r^{x}(0)=\left\{\left[p^{y}(0)\right]^{2}-\left[p^{x}(0)\right]^{2}\right\}(1-2 z)+2 z\left[p^{y}(0)-\right.$ $\left.p^{x}(0)\right]$ and, from Proposition 1, $q^{y}(0)-q^{x}(0)=2 z(1-z)\left\{p^{y}(0)-p^{x}(0)\right\}$. For the former to exceed the latter, this requires $\left[p^{y}(0)-p^{x}(0)\right]<2 z^{2} /[2 z-1]$. Hence, $r^{y}(0)-r^{x}(0)>q^{y}(0)-q^{x}(0)$.

Second, the results of bivariate probit models are presented. Table A1 presents the results of two models where award and panel are used as dependent variables. The first model retains all controls used in the full model in the auxiliary equation. The second model incorporates a new independent variable to explain the use of panels of arbitrators. The new variable clause is a dummy variable equal to one if the original contract included the Clausola Compromissoria to utilize the Camera for dispute resolution. 
Table A1: Bivariate Probit: panel

\begin{tabular}{|c|c|c|c|c|}
\hline dependent variable $=$ & $\begin{array}{l}\text { Model } 1 \\
\text { award }\end{array}$ & panel & $\begin{array}{l}\text { Model } 2 \\
\text { award }\end{array}$ & panel \\
\hline panel & 0.425 & & $-1.451 *$ & \\
\hline prof & $-0.359 *$ & $0.290 *$ & -0.205 & 0.244 \\
\hline appoint & $-0.653 * *$ & 11.474 & -0.072 & 11.15 \\
\hline lawfirm & $-0.663 * *$ & $0.828 * *$ & -0.462 & $0.775 * *$ \\
\hline hearings & $0.255 * * *$ & -0.017 & $0.248 *$ & -0.036 \\
\hline documents & $0.104 * * *$ & 0.017 & $0.128 * * *$ & 0.031 \\
\hline clause & & & & -0.707 \\
\hline content & YES & YES & YES & YES \\
\hline log-likelihood & -140.4 & -144.6 & -140.35 & -142.6 \\
\hline sum & \multicolumn{2}{|c|}{-284.9} & \multicolumn{2}{|c|}{-282.9} \\
\hline full model & \multicolumn{2}{|c|}{-284.2} & \multicolumn{2}{|c|}{-282.8} \\
\hline Wald Test of $\rho=0$ & \multicolumn{2}{|c|}{$X^{2}=2.143$} & \multicolumn{2}{|c|}{$X^{2}=0.372$} \\
\hline
\end{tabular}

As one can see, regardless of the model considered, a Wald Test illustrates that there is no correlation between the residuals of the two equations. Thus, endogeneity of panel does not seem to be present.

Similarly, Table A2 presents a bivariate probit analysis considering potential endogeneity of the selection of university professors as arbitrators. The same two models are considered. 


\begin{tabular}{|c|c|c|c|c|}
\hline dependent variable $=$ & $\begin{array}{l}\text { Model } 1 \\
\text { award }\end{array}$ & prof & $\begin{array}{l}\text { Model } 2 \\
\text { award }\end{array}$ & prof \\
\hline panel & $-0.537 * * *$ & 0.171 & $-0.557 * * *$ & 0.190 \\
\hline prof & $1.457 * * *$ & & $1.379 * * *$ & \\
\hline appoint & $-0.799 * *$ & $1.458 * * *$ & $-0.739 * * *$ & $1.496 * * *$ \\
\hline $\begin{array}{l}\text { lawfirm } \\
\text { clause }\end{array}$ & $-0.432 * *$ & $0.514 * *$ & $-0.425 * *$ & $\begin{array}{l}0.528 * * \\
-0.474 *\end{array}$ \\
\hline content & YES & YES & YES & YES \\
\hline log-likelihood & -242.0 & -222.0 & -242.0 & -220.9 \\
\hline sum & \multicolumn{2}{|c|}{-464.0} & \multicolumn{2}{|c|}{-462.9} \\
\hline full model & \multicolumn{2}{|c|}{-462.8} & \multicolumn{2}{|c|}{-461.0} \\
\hline Wald Test of $\rho=0$ & \multicolumn{2}{|c|}{$X^{2}=2.588$} & \multicolumn{2}{|c|}{$X^{2}=4.000 * *$} \\
\hline
\end{tabular}

A Wald Test of the correlation in the residuals rejects the null hypothesis of correlation in one model, but not the other. This it is unclear whether or not endogeneity is a problem with regards to the selection of university professors. It very well may be the case that the factors that drive the selection of faculty also drive the willingness to settle the dispute. 